\title{
Energy Analysis and Remixing Effect of Thermal Coupling Petlyuk Column for Natural Gas Liquid (NGL) Fractionation Train
}

\author{
Rohani Mohd Zin*, Mohd Ammar Abidin, Munawar Zaman Shahruddin \\ Chemical Engineering Faculty, Universiti Teknologi MARA (UiTM), 40700 Shah Alam, Selangor, Malaysia.
}

\begin{abstract}
In this work, a non-conventional distillation sequence with thermal coupling (Petlyuk Column) was presented as a technique to perform the separation of the NGL consist of ethane, propane, butane or other higher alkanes. The improvements were investigated through the energy analysis and remixing effect. From the result obtained, it was found that the Petlyuk arrangement consumes less amount of energy and able to reduce the remixing effects as compared to the conventional column sequencing. The Petlyuk arrangement saved about $44.49 \%$ and $12.83 \%$ in terms of cooling and heating duty, respectively. The overall annual energy saving shown by this arrangement is $39.22 \%$. This arrangement proved to be able to prevent the remixing effect occurrence that contributes to thermal and separation inefficiency. The desired separation efficiency also obtained by this arrangement as all the product specifications are met. The ability in avoiding remixing effect by the Petlyuk column permits a significant reduction in $\mathrm{CO}_{2}$ emission with an average of $29.43 \%$ of each equipment involved. Hence, it can be concluded that the Petlyuk arrangement model is a better alternative to be implemented in the NGL fractionation train.
\end{abstract}

Keywords: distillation, fractionation train, thermal coupling, Petlyuk column, remixing effect

Article History: Received: $25^{\text {th }}$ Sept 2020; Revised: $5^{\text {th }}$ February 2021; Accepted: $14^{\text {th }}$ February 2021; Available online: $18^{\text {th }}$ February 2021 How to Cite This Article: Zin, R.M., Abidin, M.A., and Shahruddin, M.Z. (2021) Energy Analysis and Remixing Effect of Thermal Coupling Petlyuk Column for Natural Gas Liquid (NGL) Fractionation Train. International Journal of Renewable Energy Development, 10(3), 459-469 https://doi.org/10.14710/ijred.2021.33094

\section{Introduction}

Distillation is both energy-intensive and efficient processes in the chemical industry, responsible for the largest fraction of an immense amount of energy consumed. Distillation operation became a major concern within the sustainability challenge for a primary target of energy-saving efforts in industrially developed (Humphrey et al., 1997, Matla-González et al., 2013, Lucero-Robles et al., 2016). Although new separation methods are continuously being explored, distillation remains the most frequently used separation process (Agrawal et al., 1999; Agrawal, 2003).

The natural gas processing plant is an example of an industry that dominates these separation processes (Manley, 1996; Devold. 2009). Natural gas liquid (NGL) is a raw material for the petrochemical industry typically consists of ethane, propane, butane or other higher alkanes in a blend (Devold 2009). To accomplish the separation of natural gas liquid (NGL), a series of conventional distillation column namely deethanizer, depropanizer and debutanizer columns is used. The separation process requires a series of distillation train because it is impossible to produce more than two products with a single distillation column. Due to tight environmental regulations and the high energy cost, there is a need to improve the energy efficiency of distillation systems in a natural gas processing plant.

Energy analysis is an important approach to understand any process and optimizing the overall energy consumption. Various energy analysis works through modelling and optimization of various real-life industry case studies have been conducted by several researchers (Hoseinzadeh et al., 2019, Kariman et al., 2019, Hoseinzadeh et al., 2020 (a), Hoseinzadeh et al., 2020(b)). Typically, for the conventional distillation arrangements energy integration method has been used to reduce energy costs (Shahruddin et al., 2019). However, the scope for energy integration of the conventional distillation columns into an overall process is often limited as the practical constraints prevent integration of distillation columns with the rest of the process (Annakou et al., 1996, LuceroRobles et al., 2016, Egger et al., 2018). Since the columns cannot be integrated with the rest of the process and the potential for heat integration is limited by the heat flows in the background process, thus attention must be turned to the distillation operation and look at unconventional arrangement opportunity.

\footnotetext{
* Corresponding author: rohanimz@uitm.edu.my
} 
The natural gas processing plant is currently using the conventional arrangement that consumes of intensive heat utilization of the overall plant (Manley, 1996, MatlaGonzález et al., 2013). Due to a large percentage of heat used in operating the distillation columns, it contributes to a large amount of operating cost and capital cost. Alternatively, non-conventional arrangements which is Petlyuk columns are the options for these problems. Petlyuk column is especially energy-efficient and due to their ability to save capital and energy cost (Fidkowski 2006, Dwivedi et al., 2013, Matla-González et al., 2013, Lucero-Robles et al., 2016, Egger et al., 2018). This unique distillation arrangements have become very attractive although it has rarely been implemented in industries due to the complex arrangement (Ramirez-Corona et al., 2010), lack of knowledge and understanding and scepticism towards practical issues such as control (Hernandez et al., 1999). For the gas processing plant industries, especially in Malaysia none of the plants has implemented any of these complex distillation arrangements yet.

Only in the recent years, the Petlyuk arrangement was successfully applied in industry for a limited amount of feed components (Matla-González et al., 2013, Errico et al., 2015, Egger et al., 2018). This indicates that these problems may be resolved by this non-conventional arrangement. Thus, in this work, the scope of knowledge extends to the complex distillation arrangements on NGL fractionation train. The present work investigates the energy analysis, purity of the final products (product specifications) and remixing effects of the thermally coupled Petlyuk column as the non-conventional arrangement in NGL fractionation train. Comparisons are made with the current conventional arrangements. The potential of reducing the $\mathrm{CO}_{2}$ emissions through the implementation of Petlyuk column is also investigated. Comparison analysis is carried out on the potential reduction of $\mathrm{CO}_{2}$ mitigation between conventional distillation column and Petlyuk column.

\section{NGL Separation}

Natural gas generally comprises $90 \%$ methane and $10 \%$ other light alkanes. In its marketable form, natural gas is processed to obtain a specific composition of hydrocarbons, sour and acid ((hydrogen sulfide $\left(\mathrm{H}_{2} \mathrm{~S}\right)$ and carbon dioxide $\left(\mathrm{CO}_{2}\right)$ ) permissible quantity and energy contents. Natural gas liquids are primarily raw materials for a petrochemical industry typically consist of ethane, propane, butane or other higher alkanes in a blend or separately (Devold 2009). As the energy demands growing, global oil resources need to be utilized to the fullest and as efficiently as possible (Underwood et al, 2015). With the increasing demands and limited resources, it has become a driver for the industry to overcome the problems and find solutions to meet the market demands. One of the methods to overcome the problem is through the optimization of the processing plant and produces high-quality products with low energy consumption and consequently cost-effective.

\subsection{Conventional NGL Fractionation Train}

A typical NGL fractionation train is shown in Figure 1 and consists of a series of conventional distillation columns. In this processing plant, the natural gas feed will be separated into individual component to produce methane, ethane propane and butane using a demethanizer, a deethanizer, a depropanizer and a debutanizer column respectively. In some other gas processing plants, the mixed butane product can be further split in a deisobutanizer to produce normal and isobutane. However, the scope of energy analysis of this work will focus on a deethanizer, a depropanizer and a debutanizer column. Future work will be done involving the de-methanizer column, as the energy utilization for the column is different from typical distillation operation since it involves a complex cryogenic separation process.

In typical gas plant (Figure 1), the NGL liquid enters the deethanizer, which separates the ethane from the mixed NGL liquid. The column operates with a partial condenser and produces a cold ethane gas product at the top of the column (as shown in Table 1). The bottom product from the deethanizer feeds the depropanizer. A propane stream is taken from the depropanizer reflux drum as the top product as indicated in Table 1 . The debutanizer removes the butane as the top product from the remaining NGL liquid. Pentane plus (pentane with higher alkanes component), or natural gasoline, is taken as a bottom product from the debutanizer as shown in Table 1 and Figure 1.

A train or sequence of separators is required because it is often impossible to produce more than two products with single separation equipment. By proceeding from the lightest hydrocarbons to the heaviest, it is possible to separate the different NGLs reasonably easily (Essam Bahnassi et al., 2005). Table 1 summarized the different types of fractionators that are considered in this study for the natural gas liquid (NGL) fractionation train.

\subsection{Non-Conventional Arrangements (Thermally Coupled - Petlyuk Column)}

One of the most important non-conventional distillation arrangements involves thermal coupling (Agrawal et al., 1999; Agrawal, 2006). In this work, the distillation sequences with thermal coupling were presented as a technique to perform a separation with less energy consumptions and reduced remixing effects as compared to the conventional simple column sequencing.

Table 1

Types of fractionator

\begin{tabular}{|c|c|c|c|}
\hline $\begin{array}{l}\text { Types of } \\
\text { fractionator }\end{array}$ & Feed & $\begin{array}{c}\text { Top } \\
\text { product }\end{array}$ & Bottom product \\
\hline Deethanizer & $\begin{array}{l}\text { NGL Liquid/ } \\
\text { (Demethanizer } \\
\text { bottom) }\end{array}$ & Ethane & Propane plus \\
\hline Depropanizer & $\begin{array}{l}\text { Deethanizer } \\
\text { bottom }\end{array}$ & Propane & Butanes plus \\
\hline Debutanizer & $\begin{array}{l}\text { Depropanizer } \\
\text { bottom }\end{array}$ & Butane & Pentanes plus \\
\hline
\end{tabular}




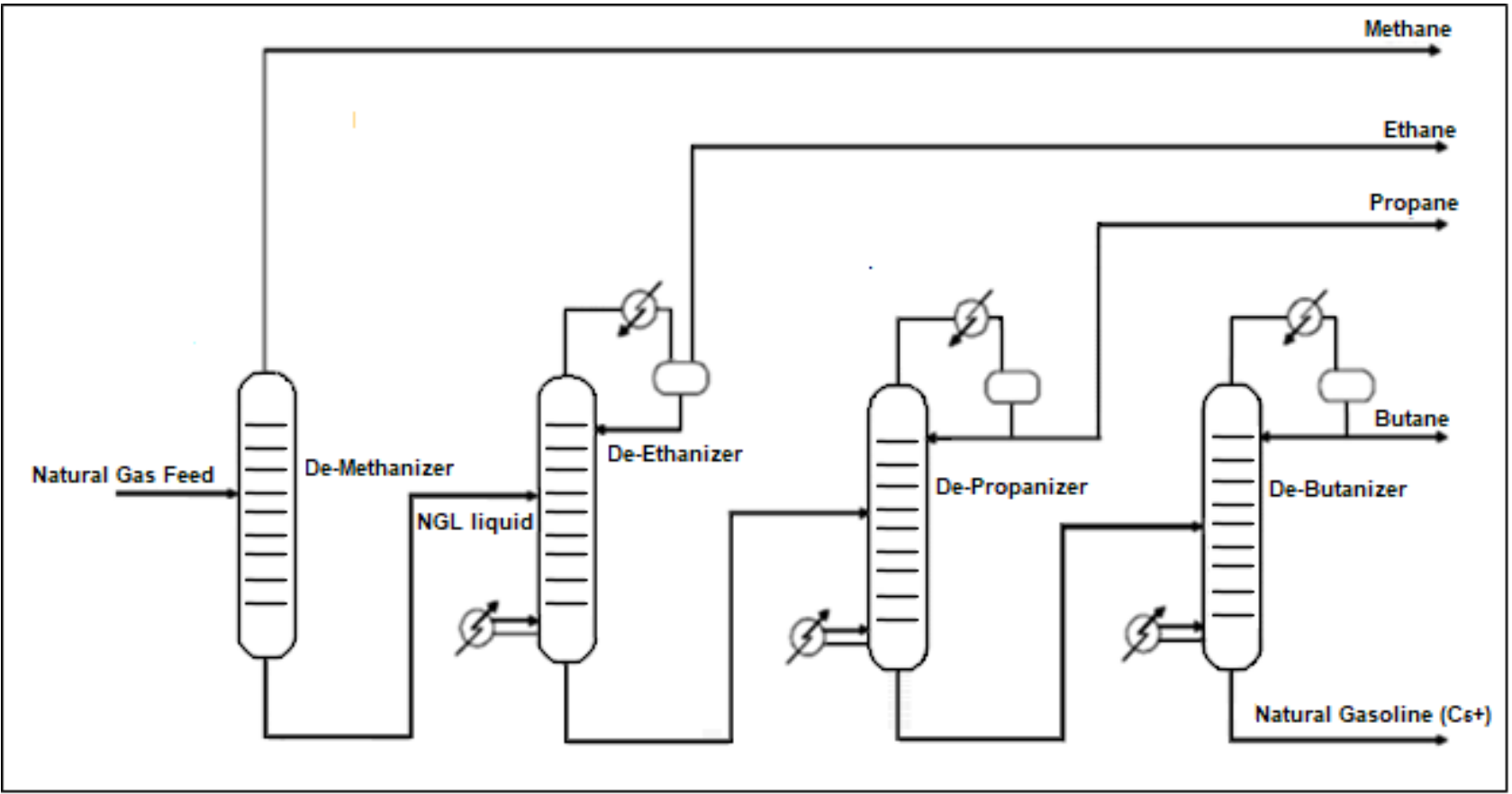

Fig 1. Conventional fractionation trains of natural gas (Essam Bahnassi et al., 2005).

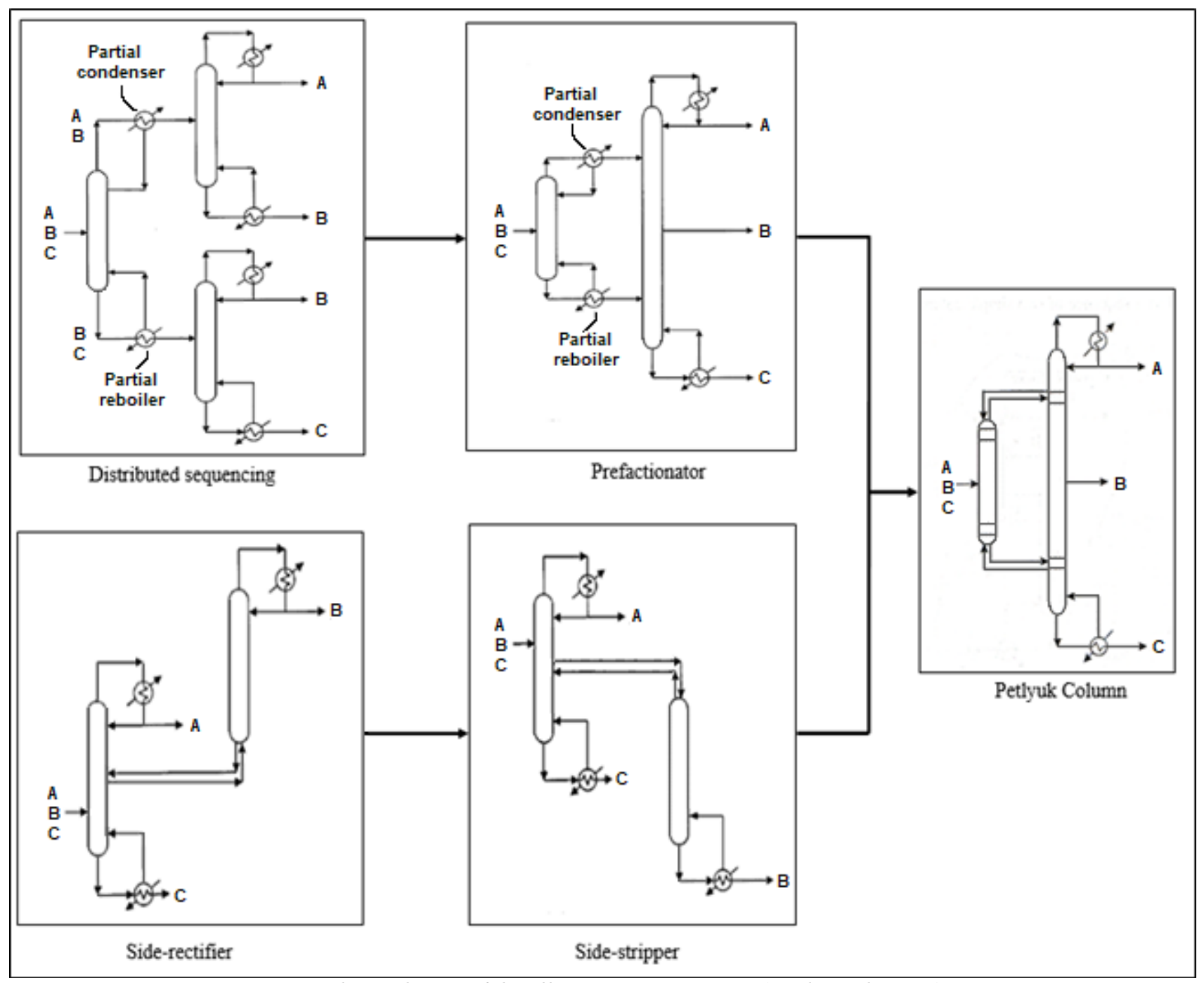

Fig 2. The evolution of distillation arrangements (Nath et al., 1981). 
A non-conventional column that realizes energy and capital cost savings is the Petlyuk column (as shown in Figure 2). This type of configuration was discovered and patented by Wright in 1949 (Underwood, 1946), but only in the last years has become more attractive and its applicability more realistic (Matla-González et al., 2013, Errico et al., 2015, Egger et al., 2018). In this configuration, the columns are thermally-coupled as illustrated in Figure 2 (Caballero et al., 2004). Thermal coupling is used to describe the situation when liquid from a column is used to supply reflux and vapour is used to supply boil-up to another column (Petlyuk et al., 1965). Several variations of this arrangement are used to eliminate heat exchangers in column designs. In this configuration, three products can be produced from the two columns with one reboiler and one condenser, as compared to a conventional arrangement.

Figure 2 shows the overall evolution from the distributed sequencing to the fractionator arrangement. Then, it evolved finally from the fractionator column to Petlyuk column. This figure also shows the evolution from the side-rectifier or side-stripper to the Petlyuk column (Nath et al., 1981). The principal limitation in employing this structure was the lack of the process design. However, with modern and more suitable mathematical knowledge, high modelling tools and dynamic simulations, the problem can be overcome (Thompson et al., 1972).

\section{$2.3 \mathrm{CO}_{2}$ Emission}

Carbon dioxide $\left(\mathrm{CO}_{2}\right)$ emission is directly related to energy consumption, thus the reduction of energy consumption it will bring significant alleviation in the emission. In the natural gas liquid (NGL) fraction train, the energy consumption is contributed by the operations of reboiler and condensers. Higher heat consumption led to higher fuel utilization particularly, in the overall steam usage for the reboilers in which consequently increase the $\mathrm{CO}_{2}$ emissions to the environment. Similarly, higher condenser duty for a distillation column also indirectly contributes to higher energy (power) consumption in the required pump to transport a large amount of cooling water needed. Hence, higher energy (power) consumption directly related to the higher emission of $\mathrm{CO}_{2}$.

\section{Methodology}

The most important part to be optimized is the distillation arrangement since it is responsible for the largest fraction of a vast amount of energy consumed. There are several process simulations packages available and mostly used for example Aspen Plus, SimSci PRO/II, and UniSim (Strausa and Skogestada, 2016). These simulation packages use sequential-modular approach for solving the flowsheet, in which each unit operation is considered as a separate block and calculated sequentially (Biegler et al., 1997). HYSYS software package was utilized in the modelling and process simulation of natural gas liquids fractionation train in this study.

HYSYS is a market-leading process modelling tool for conceptual design, optimization, performance monitoring for oil \& gas production, gas processing, and petroleum refining industries (Chowdhury, 2012). The advantages of HYSYS are it uses best-in-class process technologies and has the ability to provide process design knowledge to improve the profitability and efficiency of the business (Sultana and Amin 2011).

\subsection{Modelling and Process Simulation}

HYSYS (an abbreviation for Hyprotech Systems) is a powerful and efficient tool with a reasonable accuracy that offers a comprehensive thermodynamics model in determining the phase behaviours, transport properties as well as the physical properties of the components. It also offers a comprehensive library of unit operation models (Oyegoke and Dabai 2018, Trupti et al., 2012). HYSYS software also normally used in process modelling with the capability to provide process design knowledge (Sultana and Ruhul Amin 2011) to improve plant control and operability., The first stage in HYSYS simulation involves the definition of all components. Feed components details were entered into the flowsheet by selecting the material from the component database (Chemmangattuvalappil and Chong 2017).

Table 2 shows the compositions of the feed component and its operating conditions for the fractionation of natural gas liquids (NGL) employed in this study. The data used is the typical composition of natural gas feed-in Malaysia. Whilst Table 3 shows the product specifications of natural gas liquids (NGL) component that need to be achieved. The product specification values are based on the market requirements.

In this simulation work, consider a typical gas plant as shown in Figure 1. In this processing plant, the NGL liquid feed with composition as shown in Table 2, enters the deethanizer column. The ethane gas is separated in this column as the top product with the required minimum purity of $0.93 \mathrm{~mol}$ fraction (93 mol\%) as shown in Table 3. The bottom product from the deethanizer feeds the depropanizer and produced propane stream with a minimum purity of $93 \mathrm{~mol} \%$. The debutanizer received a feed from the bottom of the depropanizer and separates the butane from the remaining feed liquid.

Table 2

Specifications of feedstock and operating conditions for natural gas liquids (NGL) fractionation.

\begin{tabular}{lc} 
Component & Raw Feed (mole percent) \\
\hline Methane & 0.8080 \\
Ethane & 0.0566 \\
Propane & 0.0277 \\
i-Butane & 0.0094 \\
n-Butane & 0.0057 \\
i-Pentane & 0.0042 \\
n-Pentane & 0.0023 \\
n-Hexane & 0.0039 \\
n-Heptane & 0.0032 \\
n-Octane & 0.0043 \\
Carbon Dioxide & 0.0706 \\
Nonane & 0.0003 \\
Decane & 0.0006 \\
Nitrogen & 0.0032 \\
\hline Total & $\mathbf{1 . 0 0 0 0}$ \\
\hline Inlet flow rate & $21420 \mathrm{kmol} / \mathrm{hr}$ \\
Pressure & $23 \mathrm{bar}$ \\
Temperature & $-98.29^{\circ} \mathrm{C}$ \\
\hline
\end{tabular}


This butane product stream should be produced typically about $0.98 \mathrm{~mol}$ fraction $(98 \mathrm{~mol} \%)$ with allowable maximum propane content of $0.02 \mathrm{~mol}$ fraction (2 mol\%). Pentane plus (pentane with higher alkanes component) is taken out as the bottom product from the debutanizer. The pentane plus product should be produced with a requirement of maximum of $2 \mathrm{~mol} \%$ of propane content and Reid Vapor Pressure (RVP) of $83 \mathrm{kPa}$. The corresponding details on these products composition for each component can be referred to Table 3 .

Once all the components were computed, appropriate fluid packages were chosen to be assigned to estimate the conditions and properties after the simulation. In this simulation work, non-Random Two Liquid (NRTL) and Peng-Robinson fluid packages were employed for the liquid and vapour phase respectively for the simulation. Peng-Robinson fluid package was chosen since the process involves the simulation of hydrocarbon at high pressure (Chemmangattuvalappil and Chong 2017).

The simulation of conventional fractionation train was accomplished by adopting a direct sequence of four distillation columns i.e demethanizer, deethanizer, depropanizer and debutanizer (Figure 3). Each of these three columns (deethanizer, depropanizer and debutanizer) in this configuration is essentially a conventional distillation column with a reboiler and a condenser being used to carry out the separation. Hence, it is simulated using the basic distillation column in HYSYS. On the other hand, a reboiled absorber is used to simulate the demethanizer as there is no condenser in this unit. For the simulation of non-conventional fractionation thermally coupled, the separations of the individual component are achieved by adopting a sequence of demethanizer, Petlyuk column and debutanizer (Figure 4). For this simulation, the Petlyuk column is simulated using the fractionator (absorber and one main column) as opposed to typical separation. The main column and debutanizer in this configuration are essentially a conventional column with reboiler and condenser. Hence, it is simulated using the basic distillation column in HYSYS. On the other hand, an absorber is used to simulate the fractionator as there is no condenser and reboiler while a reboiled absorber is used to simulate the demethanizer as there is no condenser in this unit.

Table 3.

Product specifications of natural gas liquids (NGL) component

\begin{tabular}{|c|c|c|c|c|c|}
\hline \multirow{2}{*}{$\begin{array}{c}\text { Component } \\
\text { (mol } \\
\text { fraction) }\end{array}$} & \multicolumn{5}{|c|}{ Specification Requirement } \\
\hline & $\begin{array}{c}\text { Metha } \\
\text { ne }\end{array}$ & Ethane & Propane & Butane & $\mathrm{C} 5+$ \\
\hline Methane & $\begin{array}{l}0.85 \\
\min \end{array}$ & $0.02 \max$ & & & \\
\hline Ethane & & $0.93 \mathrm{~min}$ & $\begin{array}{l}0.02 \\
\max \end{array}$ & & \\
\hline Propane & & $0.02 \max$ & $\begin{array}{l}0.93 \\
\min \end{array}$ & $\begin{array}{l}0.02 \\
\max \end{array}$ & $\begin{array}{l}0.02 \\
\max \end{array}$ \\
\hline Butanes & & & $\begin{array}{l}0.04 \\
\max \end{array}$ & & \\
\hline \multicolumn{6}{|l|}{ Pentanes } \\
\hline $\mathrm{RVP}(\mathrm{kPa})$ & & & & & $83 \max$ \\
\hline Total Produc & lowrate & $\mathrm{mol} / \mathrm{hr})$ & \multicolumn{2}{|c|}{19670} & \\
\hline
\end{tabular}

Min : minimum mol fraction content.

Max : maximum mol fraction content/Reid Vapor Pressure (RVP)
The simulations of both conventional (Figure 3) and nonconventional with Petyluk (Figure 4) arrangement were optimized by ensuring each of the natural gas liquids (NGL) component product specifications are achieved as per requirement stated in Table 3.

\section{$3.2 \mathrm{CO}_{2}$ Emission Reduction}

For the analysis of $\mathrm{CO}_{2}$ emission, the calculations and analysis are made based on several assumption and conditions. Apart from complying with the products specification range, the operating pressure at the bottom of the column should only be in the range of medium or low-pressure steam as the heating media to minimize the operating cost. All calculations on the emissions to the environment resulting from heating and cooling duty are made based on the assumption that fuel used is pure methane and the emission is carbon dioxide. These assumptions are made based on justifications:

1) The heating duty will determine the amount of fuel required, thus directly correlate with the emissions amount to the environment resulting from the combustion process.

2) The cooling duty indirectly determines the power consumption needed by the pump to supply the required cooling water. Hence, the power consumption will have a direct correlation with the total $\mathrm{CO}_{2}$ emission.

According to Gadalla (2003), the heating equipment for example boiler and furnace, if combusted when mixed with air, $\mathrm{CO}_{2}$ emissions will be produced based on the following:

$\mathrm{C}_{x} \mathrm{H}_{y}+\left(x+\frac{y}{4}\right) \mathrm{O}_{2} \rightarrow x \mathrm{CO}_{2}+{ }_{2}^{y} \mathrm{H}_{2} \mathrm{O}$

where $x$ and $y$ denote the number of carbons, C, and hydrogen, $\mathrm{H}$, atoms which present in the fuel compositions. In this case, complete oxidation of carbon is assumed.

Typical fuels used in this heating equipment are light to heavy fuel oils, natural gas, and coal. In this work, methane is considered since it is widely being used in the current market due to more environmentally friendly feature compared to the others.

In the combustion of fuels, the air is assumed to be in an excess amount to ensure complete combustion, hence no carbon monoxide is formed. $\mathrm{CO}_{2}$ emissions are related to the amount of fuel burnt, QFuel $(\mathrm{kW})$, in heating equipment calculated based on the following equation (2);

$$
\left[\mathrm{CO}_{2}\right]_{\text {Emiss }}=\left(\frac{Q_{\text {Fuel }}}{N H V}\right)\left(\frac{C \%}{100}\right) \alpha
$$

where $(\alpha=3.67)$ is the ratio of molar masses of $\mathrm{CO}_{2}$ and $\mathrm{NHV}(\mathrm{kJ} / \mathrm{kg})$ represents the net heating value of fuel with a carbon content of $\mathrm{C} \%$ (dimensionless) (Gadalla, 2003). The amount of fuel burnt can be determined as;

$$
Q_{\text {Fuel }}=\frac{Q_{\text {Proc }}}{\lambda_{\text {Proc }}}\left(h_{\text {Proc }}-419\right) \frac{T_{F T B}-T_{0}}{T_{F T B}-T_{\text {Stack }}}
$$

where $\lambda_{\text {Proc }}(\mathrm{kJ} / \mathrm{kg})$ and $h_{\text {Proc }}(\mathrm{kJ} / \mathrm{kg})$ are the latent heat and enthalpy of steam delivered to the process, respectively $\mathrm{T}_{\text {FTB }}\left({ }^{\circ} \mathrm{C}\right)$ is the flame temperature of the boiler flue gases (Smith, 1991). 
Citation: Zin, R.M., Abidin, M.A., and Shahruddin, M.Z. (2021) Energy Analysis and Remixing Effect of Thermal Coupling Petlyuk Column for Natural Gas Liquid (NGL) Fractionation Train. Int. Journal of Renewable Energy Development, 10(3), 459-469, doi: 10.14710/ijred.2021.33094

$\mathrm{P}$ a g e $\mid 464$

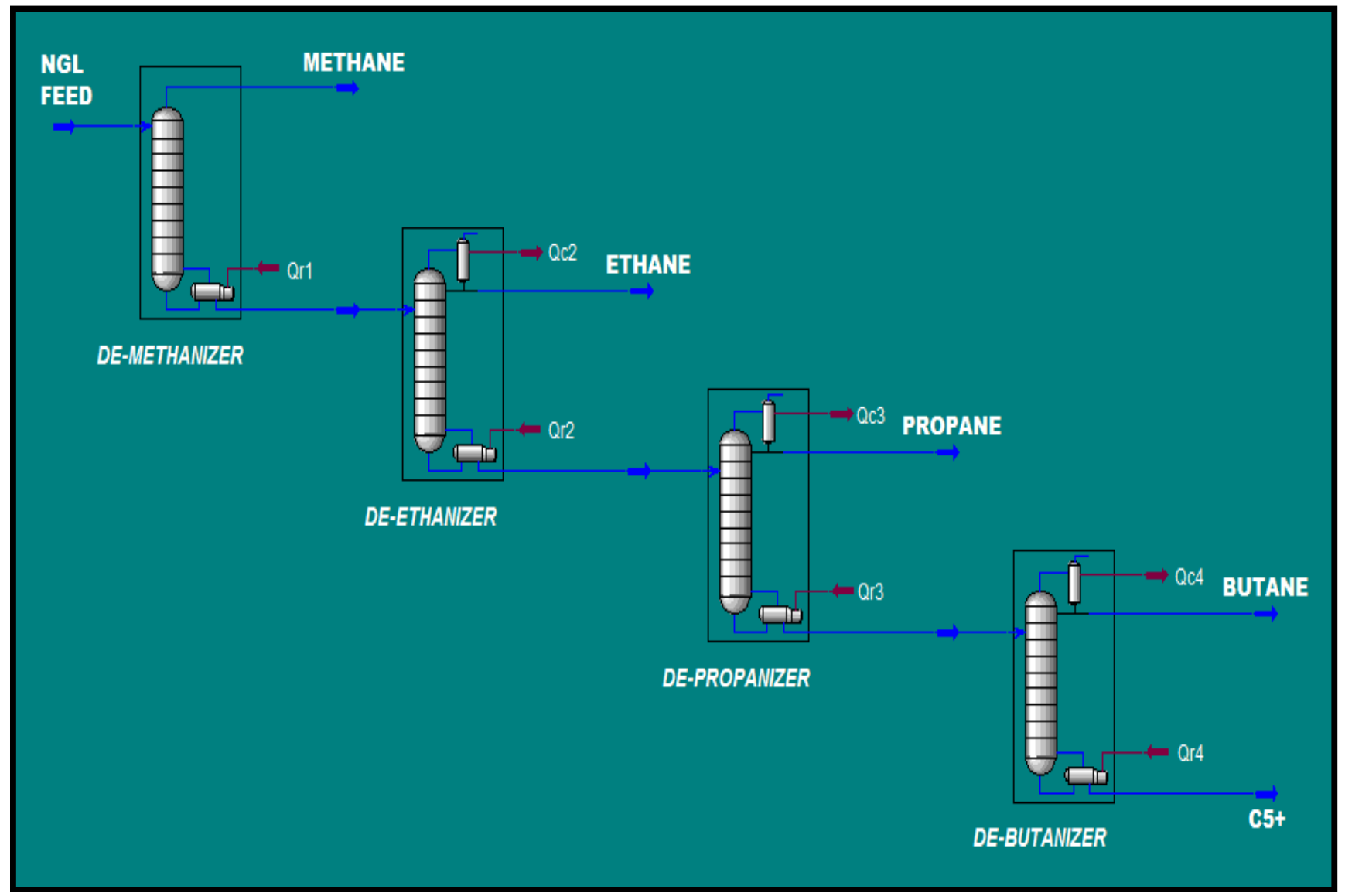

Fig 3. Rigorous simulation of conventional arrangement.

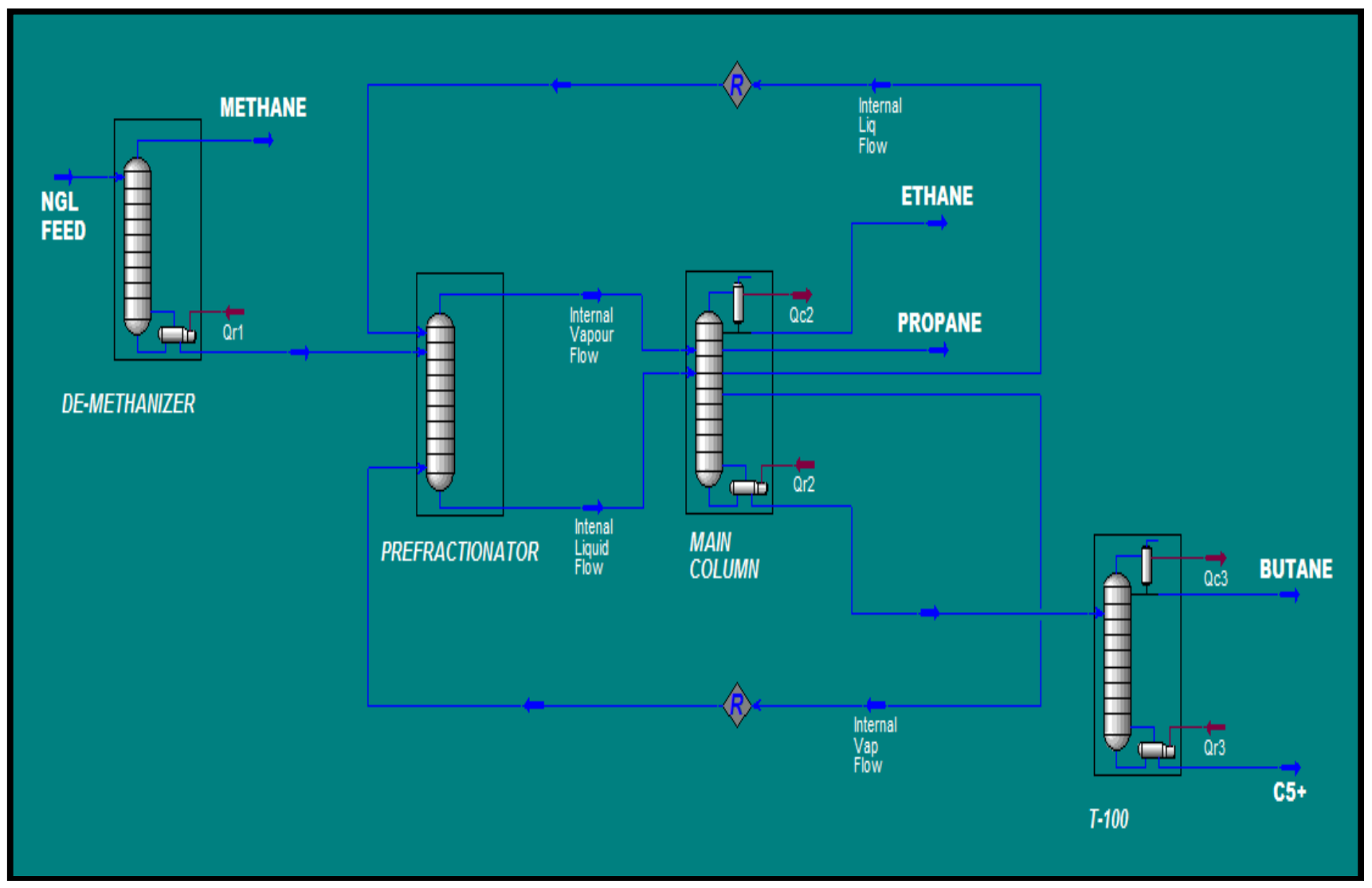

Fig 4. Rigorous simulation of non-conventional arrangement with Petlyuk column. 


\section{Results and Discussion}

As the scope of the research focusses on the NGL fractionation trains, the results will be discussed based on the energy analysis, products specifications, remixing effects of the separation involving ethane, propane, butane, and pentane plus products as well as the $\mathrm{CO}_{2}$ emission reduction analysis.

\subsection{Energy Analysis and Product Specification from} Optimized Conventional and Non-conventional Thermal Coupled (Petyluk) NGL Fractionation Arrangement.

Once the rigorous simulation converged, the conventional and non-conventional thermal coupled (Petyluk) NGL Fractionation trains were optimized. The optimized results for both configurations are summarized in Table 4. Based on the optimized results, the total heating duties and cooling duties for conventional columns arrangements are $22,869 \mathrm{~kW}$ and $114,686 \mathrm{~kW}$ respectively. Hence, for this NGL application, $137,555 \mathrm{~kW}$ of total energy is required for the separation process.

For the Petlyuk arrangement, based on optimized results, the total heating duties and cooling duties are $19,936 \mathrm{~kW}$ and $63,658 \mathrm{~kW}$ respectively. For this NGL application, about $131,475 \mathrm{~kW}$ of total energy is required for the separation process. This amount is much lower than the conventional arrangement. This, in turn would lead to a significant saving in the operating cost (indicated by the energy utilization by condensers and reboilers). The percentage of cooling and heating duty saving is $44.49 \%$ and $12.83 \%$ respectively. Based on the calculations, the overall saving in energy consumption associated with the Petlyuk arrangement is $39.22 \%$.

In term of product specifications, comparisons of simulated results with the market requirement were performed. The optimized results of the product specification were tabulated in Table 5. Overall, the product specifications for each of the component in term of mole fraction content and Reid Vapor Pressure (RVP) are achieved for all columns in both conventional and Petlyuk arrangement configurations.

Based on Table 5, the composition of methane and ethane products is similar for both arrangements. The composition of propane and butane products for both arrangements is slightly different, however still within the specification range. The purity of propane product for the conventional column is 0.9526 which slightly higher than Petlyuk arrangement with corresponding purity of 0.9309. Butane products also show a similar condition for both configurations. This is proven where the purity of butane products obtained for conventional and Petlyuk arrangement is 0.9398 and 0.9319 , respectively. For the RVP requirement, the maximum specification is $83 \mathrm{kPa}$.

Table 4

The optimized result of simulated conventional and non-conventional thermal coupling (Petlyuk) columns arrangement.

\begin{tabular}{|c|c|c|c|c|}
\hline \multirow{2}{*}{$\begin{array}{l}\text { Columns Arrangement } \\
\text { Columns }\end{array}$} & \multicolumn{2}{|c|}{ Conventional $^{\mathrm{a}}$} & \multicolumn{2}{|c|}{ Petlyuk } \\
\hline & Cooling Duty $(\mathrm{kW})$ & Heating Duty $(\mathrm{kW})$ & Cooling Duty $(\mathrm{kW})$ & Heating Duty $(\mathrm{kW})$ \\
\hline Deethanizer & 6937 & 9186 & N/A & N/A \\
\hline Depropanizer & 65277 & 8451 & 8853 & 13520 \\
\hline Debutanizer & 42472 & 5232 & 54805 & 6416 \\
\hline Sum Duty $(\mathrm{kW})$ & 114686 & 22869 & 63658 & 19936 \\
\hline $\begin{array}{l}\text { Total Duty: } \\
\text { Heating \& Cooling }(\mathrm{kW})\end{array}$ & \multicolumn{2}{|c|}{137555} & \multirow{3}{*}{\multicolumn{2}{|c|}{83594}} \\
\hline *Saving Cooling Duty (\%) & & & & \\
\hline *Saving Heating Duty (\%) & & & & \\
\hline $\begin{array}{l}\text { *Overall Saving: } \\
\text { Heating \& Cooling (\%) }\end{array}$ & \multicolumn{4}{|c|}{39.22} \\
\hline
\end{tabular}

a Results from Zin et al. (2011)

*Saving: comparison between conventional and Petlyuk column.

Table 5

Product specification of simulated conventional arrangement and non-conventional thermally coupled Petlyuk arrangement.

\begin{tabular}{|c|c|c|c|c|c|c|c|c|c|c|}
\hline \multirow{3}{*}{ Specification } & \multicolumn{5}{|c|}{ Product } & \multicolumn{5}{|c|}{ Product } \\
\hline & Methane & Ethane & Propane & Butane & $\mathrm{C} 5+$ & Methane & Ethane & Propane & Butane & C5+ \\
\hline & \multicolumn{5}{|c|}{ Conventional Arrangement } & \multicolumn{5}{|c|}{ Petlyuk Arrangement } \\
\hline $\begin{array}{l}\text { Methane (mol } \\
\text { fraction) }\end{array}$ & 0.8800 & 0 & & & & 0.8800 & 0 & & & \\
\hline Ethane (mol fraction) & 0.0385 & 0.9900 & 0.0060 & & & 0.0385 & 0.9900 & 0.0050 & & \\
\hline Propane (mol fraction) & & 0.0099 & 0.9526 & 0.0199 & & & 0.0099 & 0.9309 & 0.0099 & \\
\hline Butanes (mol fraction) & & & 0.04 & 0.9398 & & & & 0.0600 & 0.9319 & \\
\hline $\mathrm{RVP}(\mathrm{kPa})$ & & & & & 61.46 & & & & & 56.83 \\
\hline $\begin{array}{l}\text { Product Flowrate } \\
(\mathrm{kmol} / \mathrm{hr})\end{array}$ & 19670 & 456.5 & 590.6 & 300.1 & 404.4 & 19670 & 456.2 & 602.9 & 295 & 393 \\
\hline
\end{tabular}


Both arrangements show that this requirement are met which is $61.46 \mathrm{kPa}$ and $56.83 \mathrm{kPa}$ for conventional column and Petlyuk column arrangement, respectively. Even though there are some similarities and differences in term of product specifications, both simulated configurations show the correct level of design assurance as well as guarantees on the product quality.

Therefore, it can be concluded that the separation efficiency of Petlyuk column arrangement is excellent as the product specifications for each of the component in mole fraction content and RVP are met as per market requirements. Hence, it shows that the separation efficiency of the Petlyuk arrangement is at par with the conventional column but with a much lower amount of energy being utilized to carry out the required separation.

\subsection{Remixing Effect}

Consider a feed mixture to deethanizer column in the conventional arrangement consisting of mainly ethane $(\mathrm{A})$, propane $(\mathrm{B})$, and butane $(\mathrm{C})$ where $\mathrm{A}$ is the lightest and $\mathrm{C}$ the heaviest. In the deethanizer column, the concentration of $\mathrm{B}$ builds to a maximum at a tray near the bottom. On trays below this point, the amount of the heaviest component $\mathrm{C}$ continues to increase, diluting $\mathrm{B}$ so that its concentration profile now decreases on each additional tray toward the bottom of the column. Energy has been used to separate B to a maximum purity. Since $\mathrm{B}$ has not been removed at this point, it is remixed and diluted to the concentration at which it is removed in the bottoms. This remixing effect leads to a thermal inefficiency as shown in Figure 5.

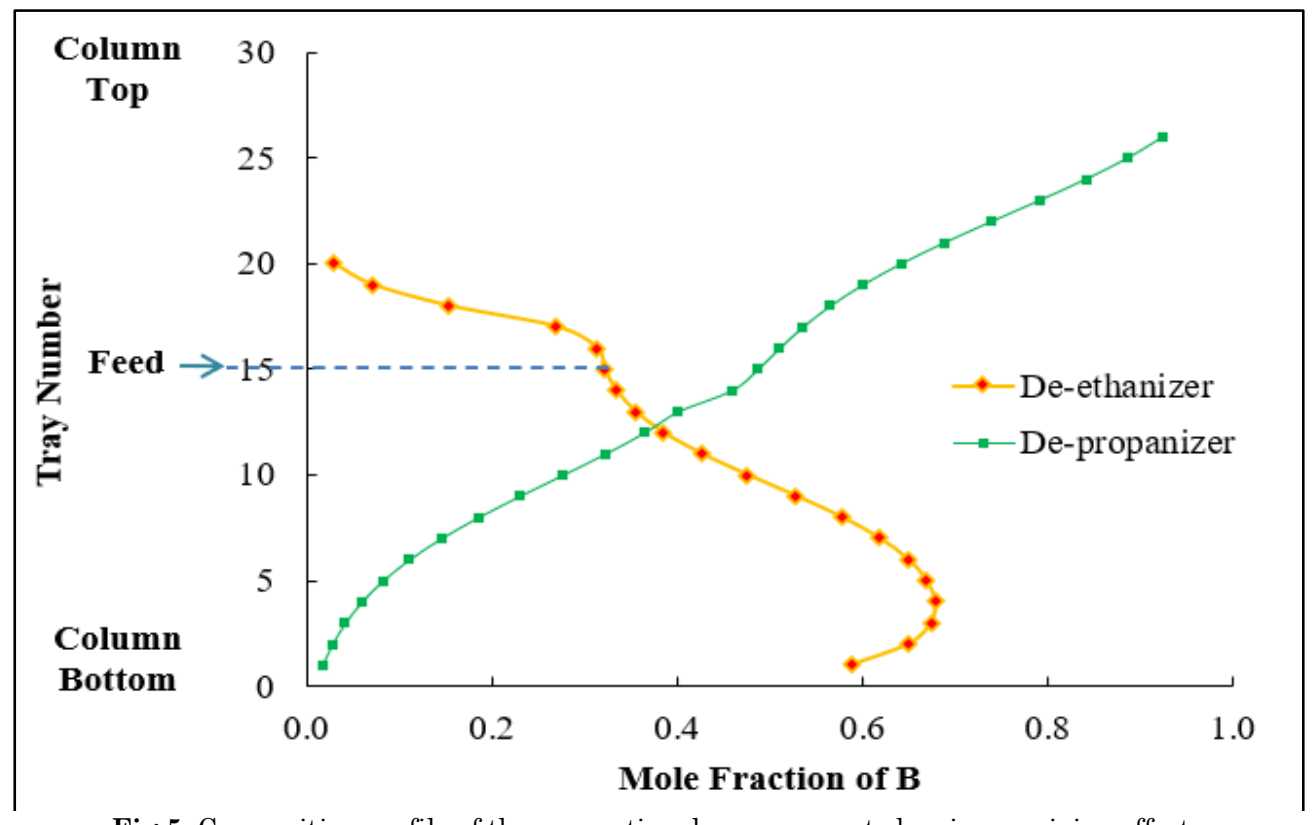

Fig 5. Composition profile of the conventional arrangement showing remixing effect.

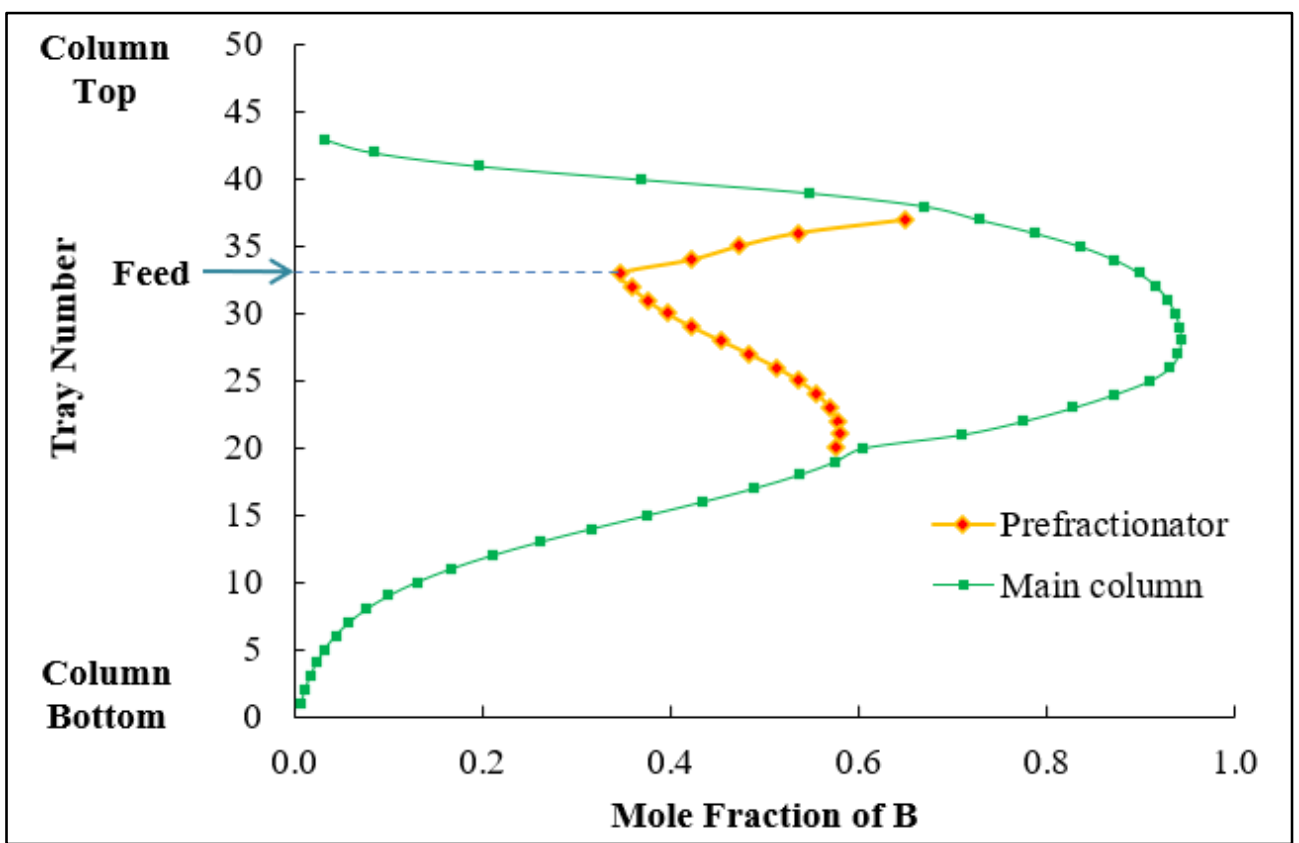

Fig 6. Composition profile of the Petlyuk arrangement showing no remixing effect occurring. 
The remixing effect occurrence is a source of inefficiency in the separation process. In comparison, considering the Petlyuk arrangement (Figure 6), a split is formed in the fractionator, leading to $\mathrm{B}$ being distributed between the top and bottom of the column separating $\mathrm{AB}$ from $\mathrm{C}$ and $\mathrm{BC}$ from A. Hence, both sections remove only one component from the product of that column section, and this is also true for all sections of the main column. In this way, the remixing effect which is a feature of the conventional sequence is avoided. Besides, it is known that losses occur in distillation operations due to mismatches between the composition of the column feed and the composition on the feed tray. As the fractionator distributes B between top and bottom, this allows greater freedom to match the feed composition with one of the trays in the column to reduce mixing losses at the feed tray. Thus, the result of this study is consistent with the previous study by Triantafyllou and Smith (1992) which explained the occurrence of remixing effect and how it can be avoided using Petlyuk column.

\section{$4.3 \mathrm{CO}_{2}$ Emission Reduction Analysis}

Table 6 summarizes the amount $\mathrm{CO}_{2}$ emission by each of the equipment involved in both conventional distillation and non-conventional (Petyluk) arrangement. Figure 7 illustrates the amount of $\mathrm{CO}_{2}$ emissions based on equipment (boiler, furnace, and gas turbine) involved in the fractionation train operation according to the column arrangement

Table 6

$\mathrm{CO}_{2}$ emission by the boiler, furnace, and gas turbine involved in the fractionation train according to the column arrangement.

\begin{tabular}{lcc}
\hline Equipment & $\begin{array}{c}\text { Conventional } \\
\text { Arrangement }\end{array}$ & $\begin{array}{c}\text { Non-conventional } \\
\text { (Petlyuk) Arrangement }\end{array}$ \\
\cline { 2 - 3 } & \multicolumn{1}{c}{$\mathrm{CO}_{2}$ Emission $(\mathrm{x} \mathrm{107} \mathrm{kg} / \mathrm{hr})$} \\
\hline Boiler & 4.23 & 2.99 \\
Furnace & 18.9 & 13.4 \\
Gas Turbine & 4.25 & 3.00 \\
\hline
\end{tabular}

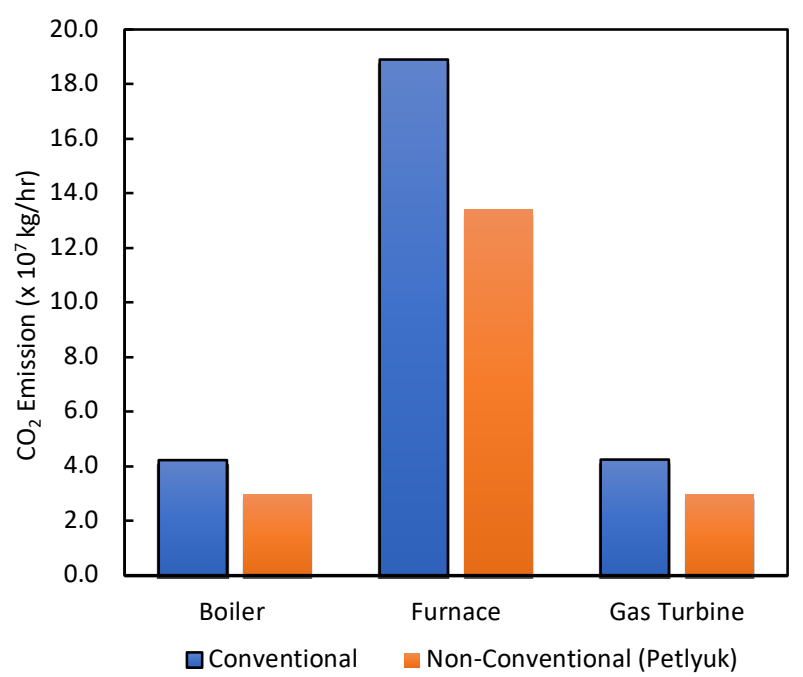

Fig 7. $\mathrm{CO}_{2}$ Emissions by boiler, furnace, and gas turbine for conventional and Petyluk Column arrangements
From Table 6 and Figure 7, the Petlyuk column arrangement exhibits the lowest $\mathrm{CO}_{2}$ emissions for each type of equipment involved. On average the percentage of saving for reduction shown by each equipment is about $29.24 \%$. As the conventional arrangement consists more of distillation columns as compared Petlyuk column arrangement, therefore more energy is required to carry out the desired duty. This resulted in more fuel consumption needed and produce a higher emission of $\mathrm{CO}_{2}$ as shown in Figure 7. Due to the feature of thermal coupling of the Petlyuk arrangement where the different columns are connected by liquid and vapour countercurrent streams which allow the remixing effect to be avoided, and consequently reducing the amount of heating and cooling energy required. This unique feature is the key reason for the $\mathrm{CO}_{2}$ emission reduction by the Petlyuk Column arrangement

\subsection{Technology Application to Other Industries.}

The use of non-conventional distillation column (Petyluk) can be extended to other industries that deal with the separation of a multi-component mixture with tight control over purity and consistency. Therefore, this technology can be applied in the production of biofuels, pharmaceutical industries, and alcoholic beverage production.

\section{Conclusion}

The energy analysis and remixing effects of natural gas liquids (NGL) fractionation process through the conventional and thermally coupled Petlyuk arrangement have been successfully carried out. Simulations were conducted out using HYSYS software. Through this study, a framework for analyzing and improving the performance of (NGL) fractionation train was provided. Synthesis of typical NGL fractionation train, steady-state simulations of conventional sequence and thermally coupled Petlyuk arrangement using HYSYS, analysis on energy consumptions, product specification, and remixing effect have been investigated. The comparisons were made, and it was found that Petlyuk arrangement saved about $44.49 \%$ and $12.83 \%$ in terms of cooling and heating duty, respectively. The overall annual energy consumption saving associated with the Petlyuk arrangement is $39.22 \%$ as compared to the conventional arrangement. In the aspect of product specifications, Petlyuk arrangement able to maintain the purity of the final products within the acceptable ranges. Petlyuk arrangement proved to be an attractive alternative column as it can avoid the remixing effect occurrence which is a very important factor to be considered since remixing condition contributes to thermal and separation inefficiency. The unique feature of thermal coupling of Petlyuk column permits significant $\mathrm{CO}_{2}$ emission reduction due to the ability to avoiding remixing effect. This is one of the key advantages acquired by the Petyluk column. From the results collected, it can be preliminary concluded that Petlyuk arrangement model is better suited to be implemented in the NGL fractionation train. However, is recommended to have a comprehensive future study to validate the results obtained and to propose solutions to overcome the technological shortcomings. Dynamic state of HYSYS modelling that mimic the real operating conditions and 
the actual equipment sizing should be carried out to verify the practicality of the Petlyuk arrangement technology implementation in natural gas fractionation train particularly on the feasibility of scale-up and economic assessment aspect. The current analysis of data in the study conducted can be utilized in the future to understand the process better. It also can become useful information to facilitate in designing and optimizing each step taken in the processing plant as well as the process equipment involved.

\section{Acknowledgments}

The authors gratefully like to thank the Ministry of Higher Education (MOHE) and Universiti Teknologi MARA (UiTM) for grants of Fundamental Research Grant Scheme (FRGS) 600-IRMI/FRGS 5/3 (053/2019) in providing financial support and for the facilities provided to conduct this study.

\section{References}

Agrawal, R. (1996) Synthesis of Distillation Column Configurations for the Multicomponent Separation. Ind. Eng. Chem. Res. 35: 1059-1071; https://doi.org/10.1021/ie950323h

Agrawal, R. (2003) Synthesis of Multicomponent Distillation Column Configurations. AIChE J. 49(2), 379; https://doi.org/10.1002/aic.690490210

Annakou, O., Meszaros, A., Fonyo, Z. and Mizsey, P. (1996) Operability Investigation of Energy Integrated Distillation Schemes. Hungarian Journal of Industrial Chemistry, 155160.

Biegler L. T., Grossmann I. E, Westerberg A.W., (1997). Systematic Methods of Chemical Process Design. Prentice Hall.

Caballero, J. A \& Grossmann, I.E. (2004) Design of distillation sequences: from conventional to fully thermally coupled distillation systems. Comp. Chem. Eng. 28, 2307-2329. https://doi.org/10.1002/aic.690180510

Chemmangattuvalappil N. \& Chong S. (2017) Chapter 11 -Basics of Process Simulation with Aspen HYSYS. Editor(s): DCY Foo, N Chemmangattuvalappil, DKS Ng, R Elyas, CL Chen, RD Elms, HY Lee, IL Chien, S Chong, CH Chong. Chemical Engineering Process Simulation, Elsevier, 233-252

Chowdhury N.B, Hasan Z., Biplob A. H. M. (2011). HYSYS Simulation of a Sulfuric Acid Plant and Optimization Approach of Annual Profit. Journal of Science 179(2), 4.

Devold, H. (2009) Oil and Gas Production Handbook. An Introduction to Oil and Gas Handbook. ABB AS. Second Edition.

Dwivedi D, Halvorsen IJ, Skogestad S. (2013) Control Structure Selection for Three-Product Petlyuk (dividing-wall) Column. Chemical Engineering and Processing: Process Intensification. $\quad 64, \quad 57-67$; https://doi.org/10.1016/j.cep.2012.11.006

Egger T., Hiller C., Fieg G., (2018) Experimental Studies of a Petlyuk Column and Validation of a Non-Equilibrium Stage Model. Chemical Engineering \& Technology 41, 827835.https://doi.org/10.1002/ceat.201700515

Errico M., Pirellas P., ROng BG, Segovia-Hernandez JG. (2015) Design and Optimization of Intensified Quaternary Petlyuk Configuration. 12th International Symposium on Process Systems Engineering and 25th European Symposium on Computer Aided Process Engineering. Elsevier. 1368-1372. https://doi.org/10.1016/B978-0-444-63577-8.50073-5
Essam Bahnassi, Abdul Rahman Khouri, Alderton, P. and Fleshman, J. (2005) Achieving Product Specifications for Ethane Through to Pentane Plus from NGL Fractionation Plants. AIChE Fall Conference

Fidkowski, T.F. (2006) Distillation Configurations and Their Energy Requirements, AIChE J. 52, 2098-2106; https://doi.org/10.1002/aic.10803

Gadalla M, Retrofit Design of Heat-Integrated Crude Oil Distillation Systems, PhD Thesis, UMIST, Manchester, UK, 2003.

Hernandez, S. \& Jimenez, A. (1999) Controllability Analysis of Thermally Coupled Distillation Systems. Ind. Eng. Chem. Res. 38: 3957-3963; https://doi.org/10.1021/ie060635s

Hoseinzadeh S., Ghasemi M.H., Heyns P. S. (2020a) Application of Hybrid Systems in Solution of Low Power Generation at Hot Seasons for Micro Hydro Systems. Renewable Energy 160, 323-332, https://doi.org/10.1016/j.renene.2020.06.149

Hoseinzadeh S., Yargholi R., Kariman H., Heyns P. S. (2020b) Exergoeconomic Analysis and Optimization of Reverse Osmosis Desalination Integrated with Geothermal Energy. Environmental Progress \& Sustainable Energy 39(5). https://doi.org/10.1002/ep.13405

Hoseinzadeh S., Zakeri M.H., Shirkhani A., Chamkha A.J. (2019) Analysis of Energy Consumption Improvements of a ZeroEnergy Building in a Humid Mountainous Area. Journal of Renewable Sustainable Energy 11, 015103. https://doi.org/10.1063/1.5046512

Humphrey, J.L. and Keller, G.E. (1997) Separation Process Technology. McGraw-Hill, New York.

Kariman H., Hoseinzadeh S., Heyns P. S. (2019) Energetic and Exergetic Analysis of Evaporation Desalination System Integrated with Mechanical Vapor Recompression Circulation. Case Studies in Thermal Engineering 16,100548. https://doi.org/10.1016/j.csite.2019.100548

Lucero-Robles E.,Gómez-Castro F. I, Ramírez-Márquez C., Segovia-Hernández J.G., Petlyuk Columns in Multicomponent Distillation Trains: Effect of its Location for the Separation of Hydrocarbon Mixtures. Chemical Engineering \& Technology, 39(12), 22072216.https://doi.org/10.1002/ceat.201600152

Manley, D. B. (1996) Distillation of Natural Gas Liquid. Proceedings of the 1996 Annual Convention, Gas Processors Association: 67-74.

Matla-González D., Urrea-García G., Alvarez-Ramirez J., Bolaños-Reynoso E., Luna-Solano G. (2013) Simulation and control based on temperature measurements for Petlyuk distillation columns. Asia-Pac. J. Chem. Eng. 8, 880-894. https://doi.org/10.1002/apj.1733

Nath, R. \& Motard, R. L. (1981) Evolutionary Synthesis of Separation Processes. AIChE J. 27(4), 578. https://doi.org/10.1002/aic.690270407

Oyegoke T \& Dabai F. (2018) Techno-Economic Feasibility Study of Bioethanol Production from a Combined Cellulose and Sugar Feedstock in Nigeria: 1-Modeling, Simulation and Cost Evaluation. Nigerian Journal of Technology. 37, 913-920; https://doi.org/10.4314/njt.v37i4.8

Petlyuk, F.B., Platonov, V.M., Slavinskii, D.M. (1965) Thermodynamically optimal method for separating multicomponent mixtures. International Chem. Eng. 5, 555561.

Ramirez-Corona N., Jimenez-Gutierrez A., Castro-Aquero A., Rico-Ramirez C. (2010) Optimum Design of Petlyuk and Divided-Wall Distillation Systems using a Shortcut Model. Chemical Engineering Research and Design. 88, 1405-1418. https://doi.org/10.1016/j.cherd.2010.02.020

Shahruddin, M.Z., Tan X., Rahimi A.N., Zubir M.A., Islam Zahran M.F., Ibrahim K.A., Abd Hamid M.K., (2019) Thermal Pinch Analysis Application on Distillation Columns Sequence of 5-Component Alcohol Mixture, Chemical Engineering Transactions, 72 https://doi.org/10.3303/CET1972046 
Smith R, Delaby O, 1991. Targeting Flue Gas Emissions. Transactions of IChemE November; Part A (69):493-505. ISSN 0263-8762

Strausa J. and Skogestada S. (2016). Minimizing the Complexity of Surrogate Models for Optimization. Computer Aided Chemical Engineering, 38, 289-294. https://doi.org/10.1016/B978-0-444-63428-3.50053-9

Sultana ST \& Ruhul Amin M., (2011) Aspen-HYSYS Simulation of Sulfuric Acid Plant. Journal of Chemical Engineering. 26: 47-49; https://doi.org/10.3329/jce.v26i1.10182

Thompson, R. W. \& King, C. J. (1972) Systematic Synthesis of Separation Schemes. AIChE J. 18(5): 941

Triantafyllou, C. \& Smith, R. (1992) The design and optimization of fully thermally coupled distillation columns. Chem. Eng. Res. Des. 70, 118-132.

Trupti A., Tyagee C., Manali K., Walker S. (2012) Simulation of Process Equipment by Using HYSYS. International Journal of Engineering Research and Applications. 41-44; https://doi.org/10.13140/RG.2.1.4186.9289

Underwood T., Erastova V., Cubillas P., Greenwell HC (2015) Molecular Dynamics Simulations of Montmorillonite-Organic Interactions under Varying Salinity: An Insight into Enhanced Oil Recovery. The Journal of Physical Chemistry C., 119: 7282-7294; https://doi.org/10.1021/acs.jpcc.5b00555

Underwood, A. J. V. (1946) Fractional Distillation of Multicomponent Mixtures Calculation of Minimum Reflux Ratio. J. Inst. Petrol: 32, 614. https://doi.org/10.1021/ie50480a044

Zin R.M., Salleh R., Sazali R.A., Kassim N.Z., (2011) Energy Efficiency in Natural Gas Processing Plant via Adoption of Complex Column (Petlyuk Column) for Sustainable Environment. 3rd International Symposium \& Exhibition in Sustainable Energy \& Environment. 36-41. https://doi.org/10.1109/ISESEE.2011.5977105 